This is a self-archived version of an original article. This version may differ from the original in pagination and typographic details. Author(s): Prati, Laura; Bergna, Davide; Villa, Alberto; Spontoni, Paolo; Bianchi, Claudia L.;
Hu, Tao; Romar, Henrik; Lassi, Ulla

Title: Carbons from second generation biomass as sustainable supports for catalytic systems

Year: 2018

Version: Accepted version (Final draft)

Copyright: @ 2017 Elsevier B.V

Rights: $C C$ BY-NC-ND 4.0

Rights url: https://creativecommons.org/licenses/by-nc-nd/4.0/

Please cite the original version:

Prati, L., Bergna, D., Villa, A., Spontoni, P., Bianchi, C. L., Hu, T., Romar, H., \& Lassi, U. (2018).

Carbons from second generation biomass as sustainable supports for catalytic systems. Catalysis Today, 301, 239-243. https://doi.org/10.1016/j.cattod.2017.03.007 


\title{
Carbons from second generation biomass as sustainable supports for catalytic systems
}

Laura Prati ${ }^{* 1}$, Davide Bergna ${ }^{2,3}$, Alberto Villa ${ }^{1}$, Paolo Spontoni ${ }^{1}$, Claudia L. Bianchi ${ }^{1}$, Tao Hu ${ }^{2}$, Henrik Romar ${ }^{2,3}$, Ulla Lassi ${ }^{2,3}$

${ }^{1}$ Università degli Studi di Milano, Dipartimento di Chimica, via C.Golgi 19, 20133 Milano, Italy, ${ }^{2}$ University of Oulu, Research Unit of Sustainable Chemistry, P.O. Box 3000, FI-90014 University of Oulu, Finland

${ }^{3}$ Kokkola University Consortium Chydenius, University of Jyvaskyla, Unit of Applied Chemistry, Talonpojankatu 2B, FI-67100 Kokkola, Finland

*Author to whom correspondence should be addressed:

laura.prati@unimi.it

\begin{abstract}
In this study activated carbons were produced from the wood of three different wood species (pine, birch, spruce). The resulting activated carbons were characterized in bulk for ash content, carbon content (elemental analyses), specific surface area, and pore size distribution, and at the surface by measuring the autogenerated $\mathrm{pH}$ and studying their structure by XPS. All the samples presented high surface areas and appeared to be mesoporous materials (mesopores $>80 \%$ ). The carbons were then used as support for AuPt nanoparticles and tested in the liquid phase oxidation of glycerol (GLY) and in the hydrogenation of levulinic acid (LA), two important chemicals from cellulose-based biomass. The catalytic results showed that the catalyst activity depends on the structural features of carbons: in GLY oxidation the most active catalyst presents the lowest content of carboxylic acid (Birch derived carbon) whereas in LA hydrogenation an higher content of aliphatic structure seems to enhance the stability and therefore the activity of the catalyst (Spruce catalyst). The structure of the carbons does not affect greatly the selectivity of both selected model reactions.
\end{abstract}

\section{Key words}

Activated mesoporous carbons; glycerol oxidation; levulinic acid hydrogenation; GVL production; carbon supported catalysts 


\section{INTRODUCTION}

Many recent reviews deals with the advantages of carbon supports for the preparation of highly dispersed metal catalysts [1-6]. Porous carbon materials like activated carbon have physical and chemical surface properties that can easily be tailored such as surface area, pore size distribution and surface acid-base characters that affect not only the metal dispersion but also the intrinsic activity of catalysts [3]. The metal-support interactions indeed can be tuned by varying the composition and the structural features of carbons [7-8]. Moreover, from a catalytic point of view the porous structure is of importance especially in the case of liquid phase reactions where diffusional limitation can be present when microporous materials are used [9].

Activated carbons can be generated starting from different C-containing precursors and normally the control on porous structure and composition is made by the careful control of the starting materials (hard or soft template syntheses)[10-11]. On the other hand an attractive feature of activated carbons is the cheapness due to the natural, low cost, large availability of the starting materials. Therefore the present study explores the possibility to use second generation biomass materials for the preparation of activated carbon to be used as support for metal nanoparticles. In particular the aim of the study has been focused on the use of sawdust samples of birch (Betula pendula), pine (Pinus sylvestris) and spruce (Picea abies) which constitute waste fractions from the saw mill in Nothern Finland, available in large quantities. These waste fractions are typically used for energy (heat) production having the heat values of $18.9,19.0$ and $19.3 \mathrm{MJ} / \mathrm{kg}$ for birch, pine and spruce, respectively.

The sawdust samples were dried at room temperature and sieved to a particle size smaller than $1.2 \mathrm{~mm}$ before being carbonized and activated in a one-step process. The obtained activated carbons are characterized by a large amount of mesopores thus promising supporting material for liquid phase catalysis. For the catalytic test we used two important reactions: the first related to the valorization of glycerol (oxidation) and the second to the transformation of levulinic acid into biofuels (reduction).

The catalysts were prepared by supporting pre-formed metal nanoparticles thus reducing as much as possible variation of size when supported. This approach allowed us to determine a correlation between the different composition of carbons and the activity of AuPt nanoparticle supported on them. Surprisingly we found that different features should be considered in the two reactions in one case privileging the activity and in the other the resistance to poisoning in the other. 


\section{EXPERIMENTAL}

Sawdust samples were supplied by sawmill located in Northern Finland. Before using the samples were room dried, and sieved to a particle size smaller than $1.2 \mathrm{~mm}$.

\subsection{Carbon synthesis and characterization}

\subsubsection{Carbonization and activation of sawdust}

Carbonization and activation of the sawdust samples was performed in a single-step process using a rotating quartz reactor inserted in a Nabertherm oven. About $400 \mathrm{~g}$ of each sample was inserted to the reactor, during the carbonization step the temperature ramped from RT to $800{ }^{\circ} \mathrm{C}$ $\left(10{ }^{\circ} \mathrm{C} / \mathrm{min}\right)$. At $800{ }^{\circ} \mathrm{C}$ the temperature was kept for 2 hour, during this period the reactor was flushed with $120 \mathrm{~g}$ /hour of overheated steam $\left(140{ }^{\circ} \mathrm{C}\right)$ produced by a steam generator using nitrogen as carrier. During the whole process the reactor was flushed with nitrogen in order to prevent oxidation of the samples. Oven was cooled down over night, continuously flushed with nitrogen. Finally carbons were taken out and dried at $105^{\circ} \mathrm{C}$ for 8-12 hours.

\subsubsection{Total carbon content (TC) and elemental analysis}

Elemental analysis was performed through Perkin Elmer optical emission spectrometer Optima 5300 DV ICP-OES.

\subsubsection{Specific surface areas and pore size distributions}

Specific surface areas and pore distributions were determined from the adsorption-desorption isotherms using nitrogen as adsorbate. Determinations were performed with a Micromeritics ASAP 2020 instrument. Portions of each catalyst (100-200 mg) were degassed at low pressure (2 $\mu \mathrm{m} \mathrm{Hg})$ and high temperature $\left(140^{\circ} \mathrm{C}\right)$ in order to clean their surfaces. Adsorption isotherms were obtained by immersing sample tubes in liquid nitrogen $\left(-196^{\circ} \mathrm{C}\right)$ to obtain isothermal conditions. Nitrogen was added to the samples in small steps and the resulting isotherms were obtained. Specific surface areas were calculated from adsorption isotherms according to the BET [12] method, while nitrogen adsorption and desorption isotherms were used to calculate the pore size distribution using the BJH method [13] With the used instrument setup $\mu$-pores down to $1.5 \mathrm{~nm}$ in diameter could be measured.

\subsubsection{Autogenerated $\mathrm{pH}$}

$\mathrm{pH}$ was measured by suspending a carbon sample $(50 \mathrm{mg})$ in a degassed $10^{-1} \mathrm{M} \mathrm{KCl}$ solution (50ml) overnight.

\subsubsection{XPS analyses and TEM images}


The X-ray photoelectron spectroscopy (XPS) were acquired with an ESCALAB 250Xi (Thermo Fisher Scientific) spectrometer using monochromatic Al Ka radiation source $(1486.7 \mathrm{eV})$ operated at $20 \mathrm{~mA}$ and $15 \mathrm{kV}$. The catalyst samples were pressed on an Indium film and the spot size of $900 \mu \mathrm{m}$ was used. The C, O, N and In were measured for all samples. The spectral analysis was carried out with Avantage V5 processing software. Charge compensation was used to determine the presented spectra and the calibration of the binding energies (BE) was performed by applying the $\mathrm{C} 1 \mathrm{~s}$ line at $284.6 \mathrm{eV}$ as reference.

A Energy filtered transmission electron microscope (EFTEM) LEO 912 OMEGA EFTEM was used to study the microstructure of the catalysts in the Center of Microscopy and Nanotechnology (CMNT) University of Oulu. The catalyst samples were dispersed in acetone and pretreated in ultrasonic bath. A small drop of microemulsion was deposited on a copper grid pre-coated with carbon.

\subsubsection{Atomic Absorption Spectroscopy}

The initial metal content and metal leaching were checked by Atomic Absorption Spectroscopy (AAS) analysis of the filtrate, on a Perkin Elmer 3100 instrument.

\subsection{Preparation of AuPt supported catalysts}

$\mathrm{NaAuCl}_{4} \cdot 2 \mathrm{H}_{2} \mathrm{O}(\mathrm{Au}: 0.031 \mathrm{mmol})$ was dissolved in $60 \mathrm{~mL}$ of $\mathrm{H}_{2} \mathrm{O}$, and PVA $(1 \%$, wt $\%)$ was added $(\mathrm{Au} / \mathrm{PVA}=1: 0.5 \mathrm{wt} / \mathrm{wt})$. The yellow solution was stirred for $3 \mathrm{~min}$, after which $0.1 \mathrm{M}$ $\mathrm{NaBH}_{4}\left(\mathrm{Au} / \mathrm{NaBH}_{4}=1: 4 \mathrm{~mol} / \mathrm{mol}\right)$ was added under vigorous magnetic stirring. The ruby-red $\mathrm{Au}(0)$ sol was formed immediately. Within a few minutes of sol generation, the gold sol was immobilized by adding the support (acidified to $\mathrm{pH} 2$ by sulphuric acid in order to maximize the electrostatic interaction between the carbon surface and the MNPs) under vigorous stirring. The amount of support was calculated as having a gold loading of $0.60 \mathrm{wt} \%$. After $2 \mathrm{~h}$, the slurry was filtered and the catalyst washed thoroughly with distilled water (neutral mother liquors). The $\mathrm{Au} /$ support was dispersed in $40 \mathrm{~mL}$ of water, with $\mathrm{K}_{2} \mathrm{PtCl}_{4}(\mathrm{Pt}: 0.021 \mathrm{mmol})$ and PVA solution $(\mathrm{Pt} / \mathrm{PVA}=1: 0.5 \mathrm{wt} / \mathrm{wt})$ added. $\mathrm{H}_{2}$ was bubbled $(50 \mathrm{~mL} / \mathrm{min})$ under atmospheric pressure and room temperature for $2 \mathrm{~h}$. The slurry was filtered and the catalyst washed thoroughly with distilled water. The total metal loading was $1 \mathrm{wt} \%$.

2.3 Catalytic tests

\subsubsection{Glycerol oxidation}


Reactions were carried out in a thermostated glass reactor $(30 \mathrm{~mL})$ provided with an electronically controlled magnetic stirrer connected to a large reservoir $(5000 \mathrm{~mL})$ containing oxygen at 3 bar. The oxygen uptake was followed by a mass flow controller connected to a PC through an A/D board, plotting a flow time diagram. The glycerol was dissolved in $10 \mathrm{~mL}$ of water, mixed the catalyst $(0.3 \mathrm{M}$ the final concentration of glycerol, glycerol $/$ metal $=500$ $\mathrm{mol} / \mathrm{mol}$ ). The reactor was pressurized at 3 bar of $\mathrm{O}_{2}$ and thermostatted at the appropriate temperature. Once the required temperature was reached, the gas supply was switched to oxygen and the monitoring of the reaction started. The reaction was initiated by stirring.

\subsubsection{Levulinic acid hydrogenation}

Levulinic acid (LA) hydrogenation was performed at $70^{\circ} \mathrm{C}$, using a stainless steel reactor $(50 \mathrm{~mL}$ capacity), equipped with heater, magnetic stirrer, gas supply system and thermometer. The LA solution $(30 \mathrm{~mL} ; 0.3 \mathrm{M})$ was added into the reactor and the desired amount of catalyst $(\mathrm{LA} / \mathrm{metal}$ ratio $=1000 \mathrm{~mol} / \mathrm{mol}$ ) was suspended in the solution. The autoclave was then purged three times with nitrogen before charging 7 bar of $\mathrm{H}_{2}$. The mixture was heated to the reaction temperature, $70^{\circ} \mathrm{C}$, and stirred (1250 rpm).

In the case of AuPt on Spruce carbon the catalyst was tested in a recycling experiment: after each run the catalyst was recovered by centrifugation and used in another experiment without any further treatment with a fresh LA solution. 2.3.3 Analysis of products

The reaction mixture, after separation from the catalysts by filtration, was analysed using high performance liquid chromatography (HPLC). Samples were removed periodically $(0.5 \mathrm{~mL})$ under stirring and analysed by high-performance liquid chromatography (HPLC) using a column (Alltech OA-10308, $300 \mathrm{~mm} \times 7.8 \mathrm{~mm}$ ) with UV and refractive index (RI) detection in order to analyse the product mixtures. $\mathrm{H}_{3} \mathrm{PO}_{4} 0.1 \mathrm{wt} \%$ solution was used as the eluent. The identification of the possible products was done by comparison with the original samples. The accuracy of the results should be considered within the range of HPLC precision (3-4\%).

\section{RESULTS AND DISCUSSION}

Carbon characterization results of before and after the activation process are presented in Table 1. Despite a very similar starting composition, the carbonized and activated samples showed different carbon contents $(88.9 \mathrm{wt} \%, 87.7 \mathrm{wt} \%$ and $77.1 \mathrm{wt} \%$ for birch, pine and spruce, respectively). Earlier, we observed that ash content of these samples was low (0.3-0.4 wt\%). The 
mass yield from each sample was calculated as mass of activated carbon divided by mass of initial sample. Yields were around 30\% after carbonization and activation, which is consistent with some earlier studies [14-15]. The relative nitrogen content remained almost unchanged before and after the carbonization and activation procedure (Table 1).

Table 1. Elemental analysis of the activated carbons before and after carbonization/activation

\begin{tabular}{|l|c|c|}
\hline Sample & $\begin{array}{c}\text { C:H:N } \\
\text { \% before activation }\end{array}$ & $\begin{array}{c}\mathbf{C : H : N} \\
\text { \% activated }\end{array}$ \\
\hline Birch & $50.52 ; 6.67 ; 0.24$ & $88.88 ; 0.99 ; 0.21$ \\
\hline Pine & $51.78 ; 6.51 ; 0.17$ & $87.44 ; 0.88 ; 0.14$ \\
\hline Spruce & $51.10 ; 6.48 ; 0.20$ & $77.09 ; 1.22 ; 0.18$ \\
\hline
\end{tabular}

The results from the analysis of surface area (BET model) and pores (BJH model) show that the steam activated samples have specific surface areas exceeding $1000 \mathrm{~m}^{2} / \mathrm{g}$ as presented in Table 2 . Even some differences regarding the pore size distribution can be envisaged, all the samples presented a large amount of mesopores $(>80 \%$ - Table 2). This latter property appears particularly attractive for liquid phase catalytic applications where diffusional limitations within the pores could strongly affect the catalytic activity of the material.

Table 2. Specific surface areas and pore size distributions

\begin{tabular}{l|cc|ccc} 
& \multicolumn{2}{|c|}{ BET } & \multicolumn{3}{c}{ Pore size distribution(\%) } \\
\hline Sample & $\begin{array}{c}\text { Specific surface } \\
\text { area }\left(\mathrm{m}^{2} / \mathrm{g}\right)\end{array}$ & $\begin{array}{c}\text { Pore volume } \\
\left(\mathrm{cm}^{3} / \mathrm{g}\right)\end{array}$ & $\mathrm{d}<2 \mathrm{~nm}$ & $2 \mathrm{~nm}<\mathrm{d}<50 \mathrm{~nm}$ & $\mathrm{~d}>50 \mathrm{~nm}$ \\
\hline Birch & 1126 & 1.0 & 12.1 & 85.0 & 2.9 \\
Pine & 1311 & 1.4 & 10.6 & 82.8 & 6.6
\end{tabular}




\begin{tabular}{l|ll|lll} 
Spruce & 1331 & 1.7 & 10.8 & 82.9 & 6.3 \\
\hline
\end{tabular}

The measurements of the auto-generated $\mathrm{pH}$ indicate a slightly lower basicity in the case of Pine derived carbon: 9.01 for Birch, 8.29 for Pine, 8.98 for Spruce.

As this study aimed to clarify the role of the chemical and physical properties of the different carbons in the catalytic activity of supported AuPt nanoparticle in the liquid phase reactions, we also investigate more in details the surface properties of the three different carbons. X-ray photoelectron spectroscopy (XPS) analysis was performed to identify surface species C1s and O1s regions showed some significant differences. Tables $3(\mathrm{O} 1 \mathrm{~s})$ and $4(\mathrm{C} 1 \mathrm{~s})$ show the quantitative analyses of the single components in the two regions. The attribution was made following the literature data.

Table 3. XPS quantitative analysis of the O1s region

\begin{tabular}{llllllll}
\hline Sample & & \multicolumn{5}{c}{$\mathrm{O} 1 \mathrm{~s}^{*}$} \\
\cline { 3 - 7 } & & Quinones & $\mathrm{C}=\mathrm{O}$ & $\mathrm{C}-\mathrm{O}-\mathrm{C}$ & $\mathrm{C}-\mathrm{O}-\mathrm{H}$ & $\mathrm{COOH}$ & $\mathrm{H}_{2} \mathrm{O}$ \\
\hline Birch & & & & & & & \\
& $\mathrm{BE}$ & 530.9 & 531.0 & 532.0 & 533.2 & 533.5 & 536.3 \\
& atom\% & 0.46 & 0.78 & 1.17 & 1.32 & 0.17 & 0.20 \\
Pine & & & & & & & \\
& $\mathrm{BE}$ & 531.0 & 531.8 & 532.7 & 533.4 & 534.0 & 536.6 \\
& atom\% & 1.32 & 1.34 & 1.56 & 0.82 & 0.81 & 0.28 \\
& & & & & & & \\
& $\mathrm{BE}$ & 530.5 & 531.4 & 532.4 & 533.7 & 534.4 & 538.5 \\
& atom\% & 0.37 & 0.74 & 2.93 & 1.31 & 0.54 & 0.04 \\
\hline
\end{tabular}

$*[16-18]$

Table 4. XPS quantitative analysis of the $\mathrm{C} 1 \mathrm{~s}$ region

\begin{tabular}{lllllll}
\hline Sample & & \multicolumn{5}{c}{$\mathrm{C} 1 \mathrm{~s}^{*}$} \\
\cline { 3 - 7 } & & Graphitic/Aliphatic & $\begin{array}{l}\mathrm{C}-\mathrm{O} / \mathrm{C}- \\
\mathrm{N}\end{array}$ & $\mathrm{C}=\mathrm{O} /$ Quinone & $\mathrm{COOH} / \mathrm{COOR}$ & $\begin{array}{l}\text { Aromatic } \\
\text { ring }\end{array}$ \\
\hline Birch & & & & & & \\
& $\mathrm{BE}$ & 284.2 & 284.7 & 285.0 & 285.5 & 289.4 \\
& atom\% & 5.90 & 28.80 & 23.95 & 9.65 & 27.60 \\
Pine & & & & & & \\
& $\mathrm{BE}$ & 284.2 & 284.6 & 284.9 & 285.5 & 290.0 \\
& atom\% & 4.99 & 19.33 & 31.10 & 10.64 & 27.64 \\
Spruce & & & & & & \\
\hline
\end{tabular}




\begin{tabular}{llllll}
\hline BE & 284.3 & 284.7 & 285.1 & 285.8 & 290.1 \\
atom\% & 9.98 & 29.34 & 19.96 & 9.79 & 24.99 \\
\hline
\end{tabular}

*[19]

Six main oxygen groups were identified. BE of $530.5 \mathrm{eV}$ corresponds to highly conjugated forms of carbonyl oxygen such as quinone [16]. The second group $(531.4 \mathrm{eV})$ can be assigned to a carbon-oxygen double bond; the one at $532.4 \mathrm{eV}$ to an ether-like single bond; whereas $\mathrm{BE}$ at $533.7 \mathrm{eV}$ can be attributed to carbon oxygen single-bonds in hydroxyl groups [17] Oxygen species at $534.4 \mathrm{eV}$ refers to the presence of carboxylic groups [18]. Some authors assign the signal at $538.5 \mathrm{eV}$, to adsorbed water and/or oxygen [18]. However, The BE of water is also debated.

In the $\mathrm{C} 1 \mathrm{~s}$ region we can identified five different components in the $\mathrm{BE}$ range of $280-296 \mathrm{eV}$. $\mathrm{C}_{1 \mathrm{~s}} \mathrm{~A}$ associated with the graphitic or aliphatic carbon. $\mathrm{C}_{1 \mathrm{~s}} \mathrm{~B}$ associated with the $\mathrm{C}-\mathrm{O}$ or $\mathrm{C}-\mathrm{N}$ (i.e., alcohol, phenol, and amine). $\mathrm{C}_{1 \mathrm{~s}} \mathrm{C}$ associated with the carbonyls and quinones. $\mathrm{C}_{1 \mathrm{~s}} \mathrm{D}$ associated with the carboxyl and ester groups. $\mathrm{C}_{1 \mathrm{~s}} \mathrm{E}, \mathrm{F}$ and $\mathrm{G}$ associated with the $\pi-\pi^{*}$ transition in aromatic rings [19].

The Pine carbon presents the highest content of quinone/carbonyl type of oxygen (Table 3) which is consistent with the corresponding C1s signal (Table 4). Conversely, the Spruce presents the highest ether type of oxygen (Table 3) consistently with the highest aliphatic contribution revealed in the $\mathrm{C} 1 \mathrm{~s}$ region (Table 4). Regarding Birch derived carbon, it can be noted that it presents the lowest content of $\mathrm{O}$ in carboxylic groups (Table 3), consistent with the highest $\mathrm{pH}$ registered.

On the carbons AuPt nanoparticles have been supported using a two steps procedure that assures the presence of bimetallic particles [20-21]. TEM analyses confirmed that in all cases the metal particles are in the range of 3-5 $\mathrm{nm}$. Figure 1 is a representative image of the samples (Birch sample). 


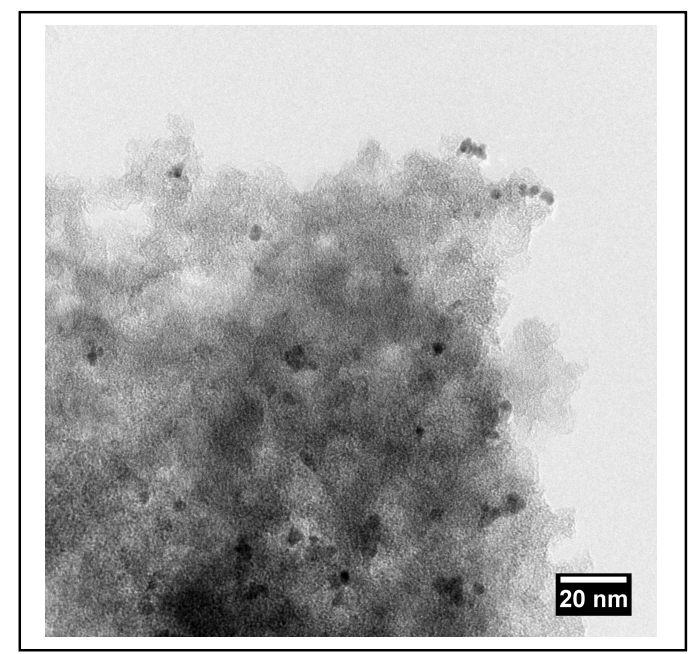

Figure 1. TEM image for 1\%AuPt/Carbon Birch

As the metallic dispersion appears very similar, we expected that the possible differences in the catalytic behavior should be addressed to the different influence of the carbon structure/surface functionalization. XPS analyses didn't show any relevant differences in terms of BE of Au or Pt. The Au4f7 had peak BE of $84.3 \mathrm{eV}$ and Pt4f7 had peak BE of $71.5 \mathrm{eV}$. The Au and Pt spectra of Birch-AuPt are shown in Figure 2.
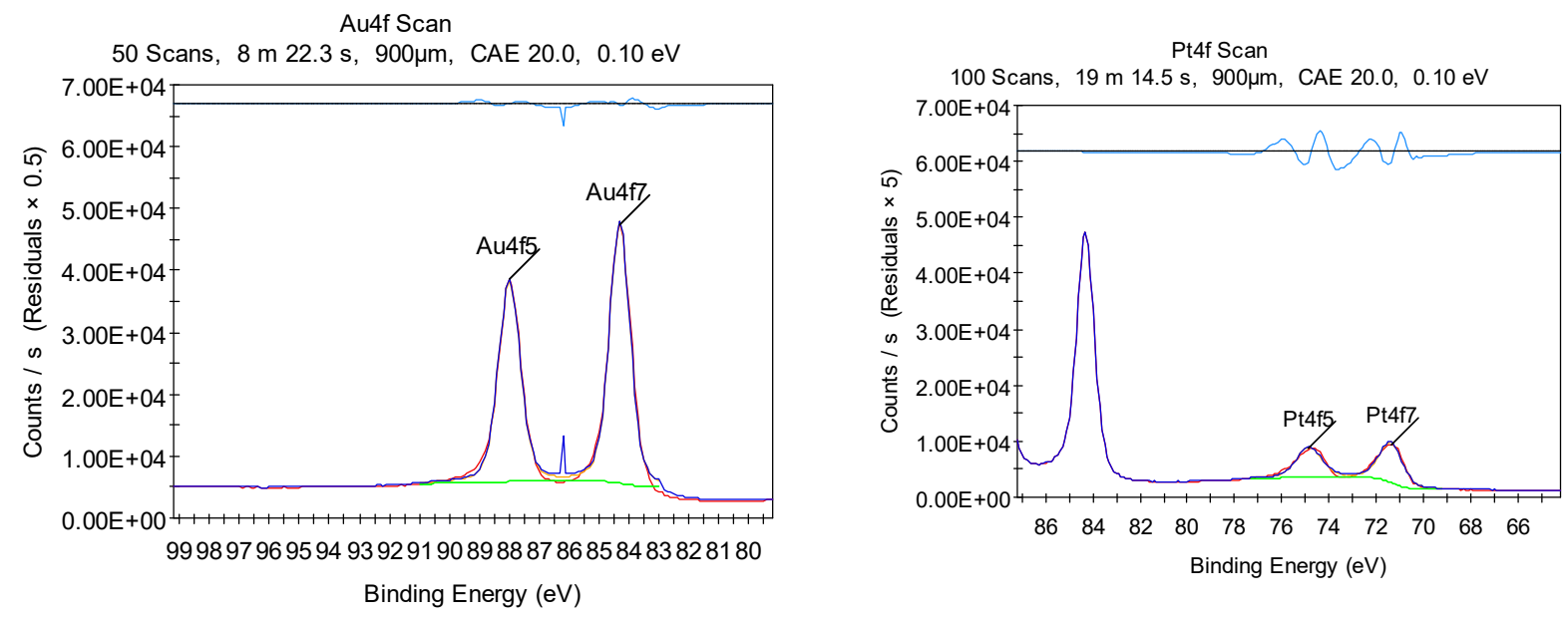

Figure 2. XPS spectra of $1 \% \mathrm{wtAuPt} / \mathrm{Birch}$ carbon 
The catalysts have been tested into two different reactions: the first one was the base free liquid phase oxidation of glycerol while the second was the hydrogenation of levulinic acid to GVL. Both these reactions have been carried out in liquid phase where the mesoporosity of carbons as the support for metal nanoparticles represents a big advantage. The reaction profiles are reported in Figure 3 for glycerol (glycerol $0.3 \mathrm{M}$, glycerol $/ \mathrm{metals}=500 \mathrm{~mol} / \mathrm{mol}, 80^{\circ} \mathrm{C}, \mathrm{pO}_{2}=3 \mathrm{~atm}$ ) and 4 for levulinic acid (LA $\left.0.4 \mathrm{M}, \mathrm{LA} / \mathrm{metals}=1000 \mathrm{~mol} / \mathrm{mol}, 70^{\circ} \mathrm{C}, \mathrm{pH}_{2}=5 \mathrm{~atm}\right)$.

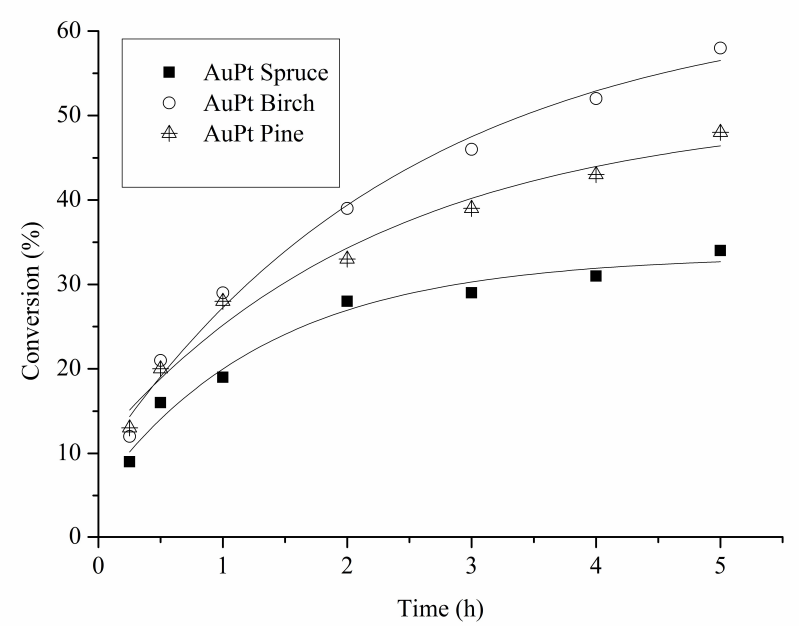

Figure 3. Glycerol oxidation profiles

AuPt nanoparticles supported on Birch derived carbon appeared more active followed by the Pine and then the Birch supported one. Thus the activities of the AuPt catalysts are in the order Birch $>$ Pine $>$ Spruce. Considering the features of the carbons revealed by XPS we concluded that a lower content of carboxylic acid is beneficial for the catalyst activity. We should also mention that in this case we cannot exclude a beneficial effect on catalytic activity of, even slight, increase in the basic properties of the carbon [22-24]. To be also noted that apparently there was no relation between the carbon nature and the selectivity of glycerol oxidation, being the differences negligible.

In the hydrogenation of levulinic acid to gamma-valerolactone (GVL), however, we observed a different trend (Figure 4). Birch and Pine catalysts behaved similarly while the Spruce one appeared the most active. 


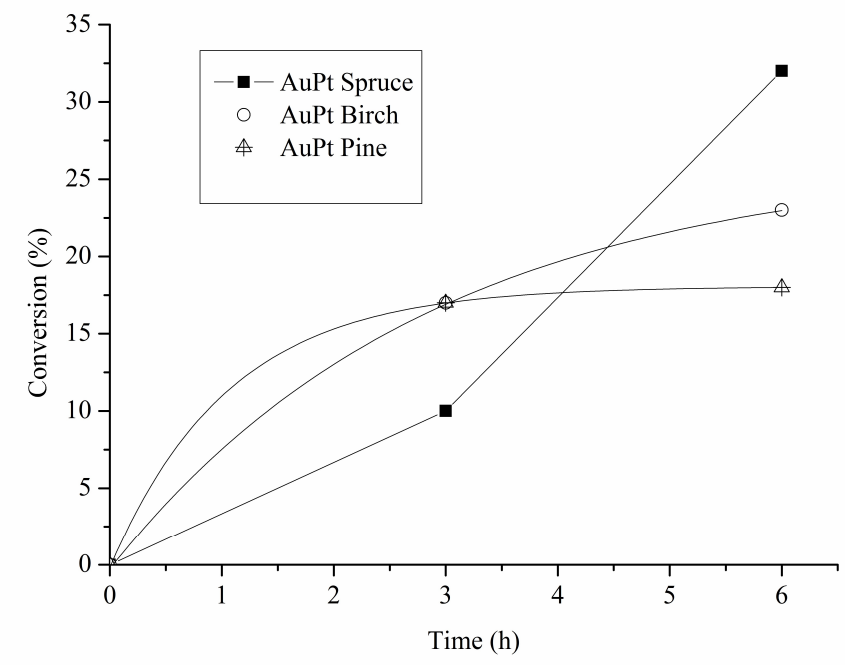

Figure 4. LA hydrogenation profiles

In particular, it is evident from the reaction profiles (Figure 4) that AuPt on Spruce carbon, differently from the other two catalysts, did not undergo deactivation even initially presents a lower activity. The catalyst was also recycled three times showing a good stability. In this case it appears that the most important factor ruling the catalyst activity is the active role of support in determining the resistance to poisoning. This is most probably produced by the highest graphitic/aliphatic contribution (from C1s XPS - Table 4) and the highest contribution of ether type oxygen (from O1s XPS - Table 3).

Also in the hydrogenation of LA, as in the case of glycerol, the selectivity was not affected by the different surface properties of the carbons.

\section{CONCLUSIONS}

Three different mesoporous carbons have been prepared using waste fractions of saw industries namely birch, pine and spruce sawdust. After carbonization and activation, the samples showed high surface area $\left(>1000 \mathrm{~m}^{2} \mathrm{~g}^{-1}\right)$ and comparable mesoporosity. However, they differ from surface functionalities as revealed by XPS study on $\mathrm{C} 1 \mathrm{~s}$ and $\mathrm{O} 1 \mathrm{~s}$ regions. The deconvolution of 
these peaks, in fact, showed the lowest content of $\mathrm{COOH}$ groups for Birch derived carbon and the highest aliphatic/aromatic structure for Spruce derived one.

After deposition of similarly sized AuPt particles, the catalysts have been tested in two important reactions, namely the selective oxidation of glycerol and the hydrogenation of levulinic acid. Both the reactions have been carried out in water under mild conditions $\left(70-80^{\circ} \mathrm{C}\right)$ and revealed a strong influence of the support structure. In the case of glycerol we observed a beneficial effect of carboxylic groups, being the AuPt supported on Birch the most effective catalyst. However in the case of levulinic acid hydrogenation the most important feature ruling out the overall catalytic activity appears the resistance of the catalyst to poisoning. In this view the carbon containing the highest content of aliphatic/aromatic structure where the oxygen is mainly of ether type appeared the most effective support, being the AuPt supported on Spruce the most active catalyst.

Even the aim of the paper is to demonstrate the efficiency as metal support of carbons derived from waste material further studies on their functionalization could be performed in order to increase the activity in both oxidation and hydrogenation reactions.

\section{Acknowledgements}

D.B. acknowledges Central Ostrobothnia Cultural Foundation (Finland) for a personal grant. EU/Interreg Nord/RENEPRO project is also gratefully acknowledged.

\section{References}

1. L. R. Radovic and F. Rodriguez-Reinoso, in Chemistry and Physics of Carbon 25, Ed. P. A. Thrower, Marcel Dekker Inc., 1997.

2. D. Tasis, N. Tagmatarchis, A. Bianco and M. Prato, Chem. Rev., 2006, 106, 1105-1136

3. L. Prati, A. Villa, A. R. Lupini and G. M. Veith, Phys. Chem. Chem. Phys., 2012, 14, 2969 2978

4. L. Prati, C. E. Chan-Thaw, S- Campisi, Alberto Villa Chem Rec., 2016, 16, 2187-2197

5. E. Lam, J.H.T. Luong, ACS Catal. 2014, 4, 3393-3410

6. F. Rodríguez-Reinoso, Carbon 1998, 36 , 159-175 
7. L. Prati, A. Villa, C. E. Chan-Thaw, R. Arrigo, D. Wang and D. S. Su, Faraday Discuss., 2011, $152,353-365$

8. R. Arrigo, S. Wrabetz, M. E. Schuster, D. Wang, A. Villa, D. Rosenthal, F. Girsgdies, G. Weinberg, L. Prati, Robert Schloegl and D. S. Su, Phys. Chem. Chem. Phys., 2012, 14, $10523-$ 10532

9. A.Villa, D.Wang, C.E. Chan-Thaw, S.Campisi, G.M. Veith and Laura Prati

Catal. Sci. Technol., 2016, 6, 598 - 601

10. I.Galbiati, C.L.Bianchi, M.Longhi, L.Formaro, A.Carrà, A., Fuel Cells 2010, 10, 251-258,

11. P.F. Fulvio, R.T. Mayes, X. Wang, S.M. Mahurin, J.C. Bauer, V. Presser, J. McDonough, Y. Gogotsi, S. Dai, Adv. Funct. Mater. 2011, 21, 2208-2215.

12. S. Brunauer, P. H. Emmett, E. Teller, J. Am. Chem. Soc., 1938, 60 (2), 309-319

13. E. P. Barrett, L. G. Joyner, P. P. Halenda, J. Am. Chem. Soc., 1951, 73 (1), 373-380

14. M.J.Antal, Jr., E.Croiset, X.Dai, C.DeAlmeida, W.S.-L. Mok, and N.Norberg Energy \& Fuels 1996, 10, 652-658;

15. M.J.Antal, Jr., S.G. Allen, X. Dai, B.Shimizu, M.S. Tam, and M.Grønli Ind. Eng. Chem. Res. 2000, 39, 4024-4031

16. J. R.Pels, F.Kapteijn, J. A.Moulijn, Q.Zhu, K. M. Thomas, Carbon 1995, 33 (11), 1641-1653

17. J. L.Figuereido, M. F. R.Pereira, M. M. A. Freitas, J. J. M. Orfao, Carbon 1999, 37 (9), $1379-1389$

18. M.Walczyk, A.Swiatkowski, M.Pakula, S. J.Biniak, Appl. Eectrochem. 2005, 35 (2), 123130

19. M.Sansotera, C.L. Bianchi, G.Lecardi, G.Marchionni, P.Metrangolo, G.Resnati,and W. Navarrini Chem. Mater. 2009, 21, 4498-4504

20. A.Villa, G. M. Veith, L. Prati, Angew. Chem. Int. Ed. 2010 49, 1 - 5.

21. D.Wang, A.Villa, F.Porta, L.Prati, D.S.Su, J. Phys. Chem. C 2008, 112, 8617-8622 
22. B. N Zope, D. D. Hibbits, M.Neurock, R. J. Davis, Science 2010, 330, 74-78

23. A Villa, N.Dimitratos, C.E.Chan-Thaw, C.Hammond, L.Prati, G.J.Hutchings, Acc. Chem. Res., 2015, 48, 1403-1412

24. A.Villa, S.Campisi, K.M.H. Mohammed, N.Dimitratos, F.Vindigni, M.Manzoli, W. Jones, M.Bowker, G.J. Hutchings and Laura Prati Catal. Sci. Technol. ,2015, 5, 1126-1132 